\title{
Author Correction: Optoelectronic mixing with high-frequency graphene transistors
}

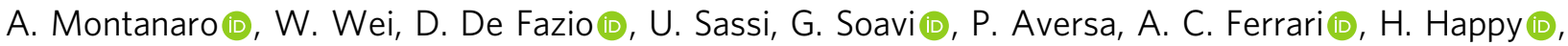 \\ P. Legagneux \& E. Pallecchi (i)
}

Correction to: Nature Communications https://doi.org/10.1038/s41467-021-22943-1, published online 12 May 2021.

The original version of this Article contained an error in Fig. 7 and Fig. 8a, c, in which the unit on the vertical axes incorrectly read " $\mu S$ ". This has been corrected to "S" in both the PDF and HTML versions of the Article.

Published online: 03 June 2021

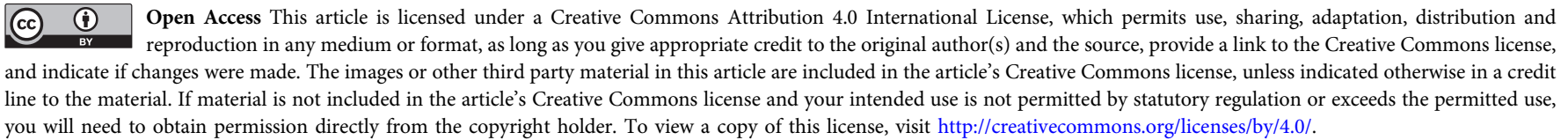

you will need to obtain permission directly from the copyright holder. To view a copy of this license, visit http://creativecommons.org/licenses/by/4.0/.

(C) The Author(s) 2021 